\title{
PEMANFATAAN TYPEFACE DELIVO SEBAGAI INSPIRASI HIASAN DEKORASI INTERIOR
}

\author{
Ivo Ramadhani \\ Program Studi Desain Interior, Universitas Potensi Utama \\ Email:ivor205@gmail.com
}

\begin{abstract}
ABSTRAK
Berkembangnya bisnis hiasan interior baik didalam Negeri maupun luar Negeri sehingga membuat seorang desainer membutuhkan ide untuk melahirkan inpari-inpirasi baru dalam menciptakan produk hiasan interior. Typeface delivo merupakan karya yang terinspirasi berdasarkan dari budaya Melayu Deli Kota Medan dalam bentuk soft file data font (TTF). Melayu Deli adalah salah satu kebudayaan bersejarah yang berada di Provinsi Sumatera Utara Kota Medan. Dekorasi merupakan kemampuan pemikiran yang digunakan untuk menghias dan memperindah suatu ruang bangunanbanguan hunian maupun ruangan publik. Penelitian ini menggunakan pendekatan teori teori estetika morfologi Thomas Munro. Hasil penelitian menunjukkan penerapan typeface delivo memiliki nilai fungsi hiasan ruang interior dan dapat diterapkan diberbagai media hiasan interior yang berupa produk untuk memperindah ruangan seperti pajangan dengan kata-kata mutiara, papan data, dan huruf-huruf yang terbuat dari kayu dan bahan-bahan kaca.
\end{abstract}

Kata Kunci : Typeface Delivo, Hiasan Dekorasi, Interior

\begin{abstract}
The development of interior decoration business both within and outside the country so as to make a designer need an idea to give birth to new inspiration in creating interior decoration products. Typeface delivo is an inspired work based on Melayu Deli Medan's culture in the form of soft file data font (TTF). Melayu Deli is one of the historical cultures in the Province of North Sumatra, Medan City. Decoration is the ability of thought that is used to decorate and beautify a building space - residential buildings and public spaces. This study uses Thomas Munro's morphological aesthetic theory approach. The results showed that the application of typeface delivo has the value of interior space decoration functions and can be applied in various interior decoration media in the form of products to beautify rooms such as displays with aphorisms, data boards, and letters made of wood and glass materials.
\end{abstract}

Keywords: Typeface Delivo, Decoration, Interior

\section{PENDAHULUAN}

Hiasan merupakan suatu benda yang dimanfaatkan untuk menghias dan memperindah tempat agar terlihat lebih menarik sehingga lebih indah dipandang mata. Pemanfaatan hiasan biasanya lebih cenderung pada ruang interior baik ruang pekerjaan, ruang fasilitas umum, ruang rumah dan ruang interior lainnya. Hiasan interior terdiri dari berbagai macam bentuk, rupa dan memiliki beragam macam tema mulai dari pewarnaan cat tembok dan penggunaan hiasan dekorasi, selain itu pada umumnya hiasan interior hanya motif-motif yang bersifat 
monoton dan sering dijumpai, dengan begitu hal tersebut membuat beberapa orang ingin mencari inspirasi yang berbeda dari yang lain. Seiring perkembangan zaman hiasan interior yang bertema budaya sangat mulai diminati oleh beberapa pihak terutama bagi mereka yang tertarik dengan kebudayaan.

Typeface delivo adalah sebuah karakter huruf yang memiliki karekteristik dan keunikan yang terbentuk dari suatu motif ragam hias kebudayaan Melayu Deli kota Medan yang berwujud dalam bentuk soft file data font serta memiliki perbedaan dengan kumpulan jenis huruf lain lainnya. Typeface delivo merupakan jenis huruf dekoratif yang dapat dimanfaatkan menjadi sumber inspirasi suatu hiasan ruang interior seperti hiasan dinding dengan cara mural dan pajangan kreatif lainnya yang memiliki nilai estetika.

Dekorasi merupakan kemampuan pemikiran yang digunakan untuk menghias dan memperindah suatu ruang bangunan-banguan hunian maupun ruangan publik. Fungsi dekorasi yaitu untuk menciptakan dan menghidupkan suasana yang terlihat biasa saja kemudian dirubah menjadi agar lebih terlihat imajinatif sehingga suasana ruang yang didekorasi menjadi lebih hidup.

Tujuan dari penelitian ini yaitu untuk meningkatkan nilai typeface delivo sebagai komponen aksesoris hiasan interior dengan sasaran dapat menghasilkan alternatif produk kerajinan yang dapat dimanfaatkan. Upaya menciptakan karya-karya yang berbobot serta mempunyai nilai estetik dan simbolis yang tinggi sangat menuntut kreatifitas desainer. Sebab untuk bisa dikatakan karyanya secara kreatif, desainer harus mampu memancarkan keunikan baru pada rancangannya yang dapat diamati dari kepandaiannya menemukan halhal yang baru.

Menurut penjelasan, yang dikutip oleh Widianti. A.K, dkk., menerangkan bahwa "secara fungsional, suatu ornamen juga harus mampu membentuk suatu karakter elemen identitas, meskipun diolah sedemikian rupa untuk memperlihatkan keindahannya, namun pada hakekatnya benda-benda alam yang dijadikan bentuk-bentuk hiasan masih menampakkan identitasnya. Estetika, etika dan logika merupakan dasar-dasar pertimbangan dalam mencari, mengolah dan menempatkan ragam hias yang mengambil tiga kehidupan di bumi, manusia, binatang (fauna) dan tumbuh-tumbuhan (flora)" (Arsitektur Tradisional Daerah Bali, 1981/1982).

Interior ruangan merupakan ruangan yang paling diperhatikan ketika sedang berada dalam ruangan, manusia cenderung berpersepsi. Persepsi tersebut dipengaruhi oleh indra manusia saat memasuki dan berada didalam sebuah ruang. Panca indra ini terdiri dari penglihatan, pendengaran, peraba, penciuman, dan perasa yang berfungsi sebagai sistem sensorik manusia. Panca indra menangkap informasi yang ada pada lingkungan sekitar dan menjadi input untuk diproses oleh otak manusia, kemudian respon dan persepsi sebagai outputnya.

Menurut pemahaman Caan (2011: 32) seperti yang dikutip oleh Thamrin, "bahwa peran interior dalam mendekorasi dan mengisi bukan untuk menciptakan sebuah lingkungan eksklusif dari dunia, melainkan sebuah jembatan antara realitas dunia dan kondisi ideal yang dibutuhkan oleh 
penggunanya, maka dekorasi dan isi yang dipilih oleh desainer interior maupun arsitektur juga patut dipikirkan sebagai media penghubung antara manusia dengan lingkungannya (Thamrin, 2016:168).

\section{STUDI LITERATUR}

Studi literatur merupakan pencarian refrensi teori-teori yang berkaitan dengan permasalahn yang ditemukan. Teknik studi literatur berfungsi untuk mendapatkan landasan teori dan informasi yang dibutuhkan oleh peneliti. Adapun studi literatur dalam acuan penulisan makalah ini adalah sebagai berikut :

\section{Desain Interior}

Berdasarkan Kamus Besar Bahasa Indonesia (2008, h.348) seperti yang dikutip oleh Ariyanti. Novarikha, dkk., kata desain dan interior memiliki arti motif atau corak ruang dalam gedung. Desain interior merupakan kegiatan merencanakan, menata dan merancang ruang dalam bangunan. Penataan suatu ruang bertujuan agar pengguna merasa nyaman, betah dan senang berada di ruangan tersebut (Ariyanti. Novarikha,dkk,Vol.3,No.11:1869).

\section{Desain Dekorasi}

Dekorasi merupakan suatu tindakan menghiasan suatu ruang baik ruang dalam maupun ruang luar yang bertujuan untuk memperindah ruangan tersebut dan memberikan kesan nyaman terhadap penghuninya.

\section{Studi Penggunaan}

Penggunaan Typeface delivo memerlukan arah target penggunaan wujud dari bentuk huruf sebagai pemanfaatan hiasan ruang interior sesuai dengan gaya desain, pewarnaan dan citra interior. Target penggunaan produk Typeface delivo sebagai hiasan adalah bangun perkantoran, fasilitas umum, dan rumah hunian, yang biasanya memiliki karakteristik sebagai berikut : 1) mengutamakan produk-produk interior yang fungsional tetapi memiliki harga yang ekonomis; 2) bentuk yang disukai oleh khalayak orang yaitu seperti bentuk yang simple namun memiliki nilai estetika yang tinggi serta menonjolkan nilai kebudayaan.

\section{Studi Warna}

Pemilihan warna yang disarankan dalam dekorasi ruang interior yaitu pemilihan warna yang terang untuk aksen dekoratif huruf agar terlihat kontras dengan interior sekelilingnya.

Menurut Zein, dkk., menyatakan bahwa: "Pendekatan perasaan nyaman seseorang jika berada di dalam ruangan dan lingkungan yang khusus dirancang untuk meringankan beban pikiran dan jiwa adalah dengan menyelaraskan hubungan manusia dengan alam melalui pendekatan interior sebagai konsep penyembuhan. Warna pada interior mempengaruhi proses penyembuhan penderita itu sendiri. Ilmu yang menggunakan warna untuk terapi disebut colourology (menggunakan warna untuk meyembuhkan). Metode ini sudah dipraktekkan oleh banyak kebudayaan kuno seperti Mesir dan Cina” (Zein, dkk, 2013:10). 


\section{PEMBAHASAN}

Akhir-akhir ini, cukup banyak ditemukan hiasan berupa aksara, baik dalam interior hunian, ataupun di ruang publik. Biasanya penggunaan huruf atau yang biasa disebut dengan tipografi lebih sering dipakai dalam pembuatan layout buku, sablon baju, hingga kebutuhan bidang periklanan, tetapi pada saat ini tipografi mulai merambah kebidang interior, khususnya bagi interior hunian, yang memerlukan sentuhan pribadi penghuninya dengan cara yang relatif mudah, bahkan tidak jarang, aksen rangkaian huruf dekoratif mengadaptasi kalimat-kalimat inspiratif yang dilontarkan oleh tokoh besar sehingga ruang-ruang pada rumah hunian ataupun ruang publik menjadi lebih unik, bermakna, dan mencerminkan kepribadian.

Tipografi adalah sebuah ilmu dalam memilih dan menata huruf disesuaikan dengan ruang-ruang yang tersedia demi memberi kesan tertentu dan bertujuan agar para pembaca dapat mendapatkan kenyamanan pada saat membacanya.

Typeface delivo merupakan hasil rancangan jenis huruf dekoratif berdasarkan ide gagasan motif ragam hias Melayu Deli kota Medan yang dirancang kedalam bentuk soft file data font (software). Jenis huruf typeface delivo juga dapat diaplikasikan sebagai media hias dekorasi ruang interior dengan meniru huruf typeface delivo sebagai alternatif pemilihan hiasan dekorasi dinding ruang interior. Pemanfaatan typeface delivo dapat dijadikan inspirasi sebagai hiasan dekorasi berupa ukiran dengan bahan pendukung ataupun tulisan dalam bentuk media lainnya, hal ini karena typeface delivo memiliki karakter huruf yang bersifat dekoratif dan memiliki nilai estetika kebudayaan Melayu Deli. Typeface delivo dapat menghiasi bagian-bagian yang lebar dan memanjang pada ruang interior, baik berupa segi empat, segi empat panjang, baik tempatnya di tengah, dipinggir atau bidang-bidang yang lebar sesuai dengan kebutuhannya sehingga ruang interior akan terlihat lebih unik dengan menggunakan hiasan dekorasi typeface delivo. Berikut adalah bentuk soft file data font (software. typeface delivo yang dapat diinstal ke komputer.

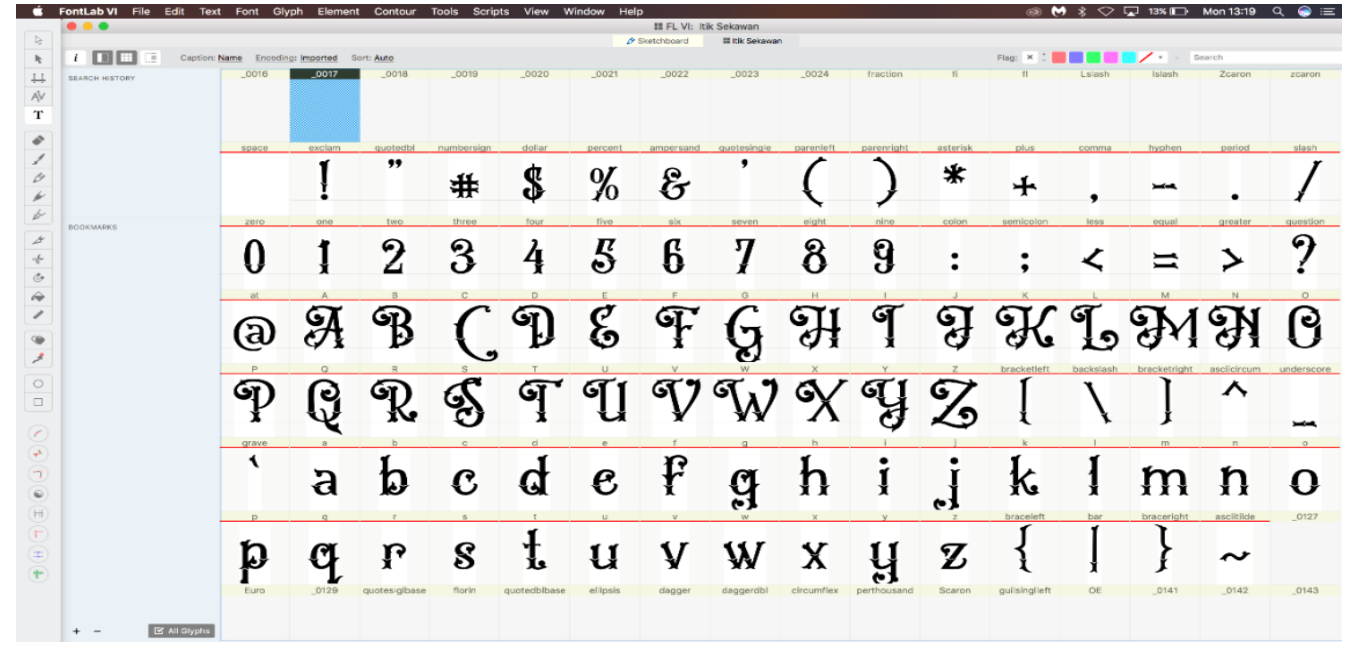

Gambar 1. Bentuk typeface delivo melalui proses install soft data font (Sumber : Ivo Ramadhani, 2018) 


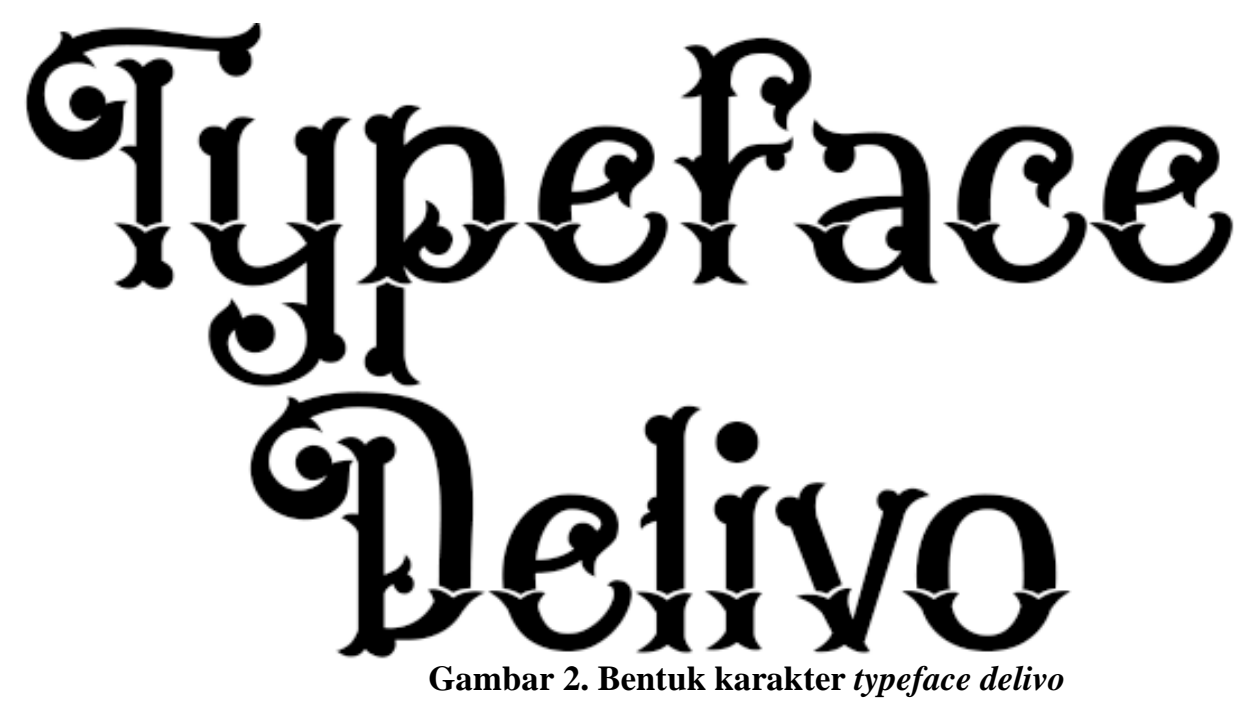

(Sumber : Ivo Ramadhani, 2018)

\section{Teori Estetika Morfologi Thomas Munro}

Seni mempunyai beragam ekspresi, segalanya tergantung dari imajinasi sang seniman mengekspresikannya, oleh karena itu seni tidak memiliki pedoman yang pasti dalam penilaiannya. Hal tersebut mengakibatkan banyaknya macam seni yang ada dan semakin bertambah mengikuti keinginan seniman yang menciptakannya. Penilaian terhadap sebuah karya seni tidak bisa dilakukan secara objektif karena itu berdasarkan unsur subyektif tiap orang. Oleh karena itu, untuk mempermudah dalam menganalisis, mendeskripsikan, dan mengklasifikasikan sebuah karya seni, menggunakan pendekatan estetika morfologi (bentuk). Estetika morfologi bukan menilai sebuah karya itu baik atau buruk tetapi lebih memudahkan dalam mendeskripsikan bentuk, style dan ekspresi sebuah karya seni (Munro, 1956:160).

Bentuk adalah beberapa elemen yang memiliki nilai keindahan dengan detail untuk tujuan tertentu. Nilai estetika dalam sebuah benda tidak dibatasi oleh benda yang berasal dari alam ataupun buatan manusia, semua benda memiliki nilai estetisnya sendiri. Segala sesuatu yang tampak dari benda tersebut (visual) memiliki elemen-elemen seni (garis, bentuk, dan warna) di dalamnya, baik itu alami ataupun buatan (Munro, 1956:161). Dalam menganalisis estetika bentuk sebuah objek, ada beberapa kesulitan selain dari banyaknya bentuk yang ada. Sebuah karya seni, ada yang berbentuk simple dan dapat terlihat secara kasad mata, seperti pyramid. Objek seperti ini lebih mudah dianalisis daripada objek yang memiliki bentuk yang kompleks dan mengandung banyak makna, untuk itu harus ada standar mengenai prinsip-prinsip dalam organisasi bentuk dan elemen-elemen pembentuknya (Munro, 1956:186-187).

Typeface delivo diterapkan pada media-media pendukung sebagai hiasan ruang interior baik berupa hiasan dinding maupun pajangan sesuai dengan kebutuhan akan keindahan suatu ruangan dan memberikan kesan kenyamanan oleh penghuni ruangan tersebut. Berikut penerapan bentuk typeface delivo pada media ukir menggunakan bahan kayu triplek dengan ketebalan $5 \mathrm{~cm}$ dan pada media cetak. 
1. Penerapan typeface delivo pada bahan kayu triplek yang diukir menjadi tulisan "UPU" sebagai hiasan pajang diatas meja.

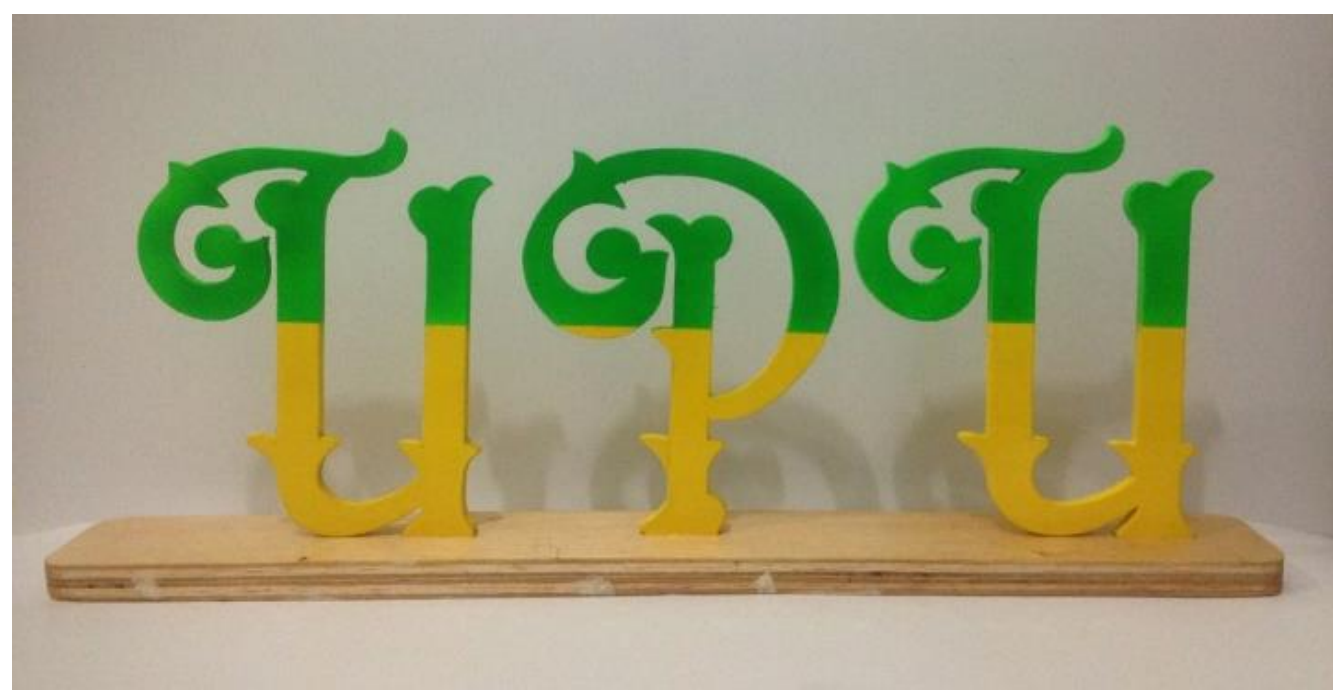

Gambar 3. Bentuk hiasan pajangan typeface delivo pada media kayu tripleks (Sumber : Ivo Ramadhani, 2018)

2. Penerapan typeface delivo pada berbagai media cetak seperti poster hiasan dinding yang menggunakan jenis tulisan tyepeface delivo.

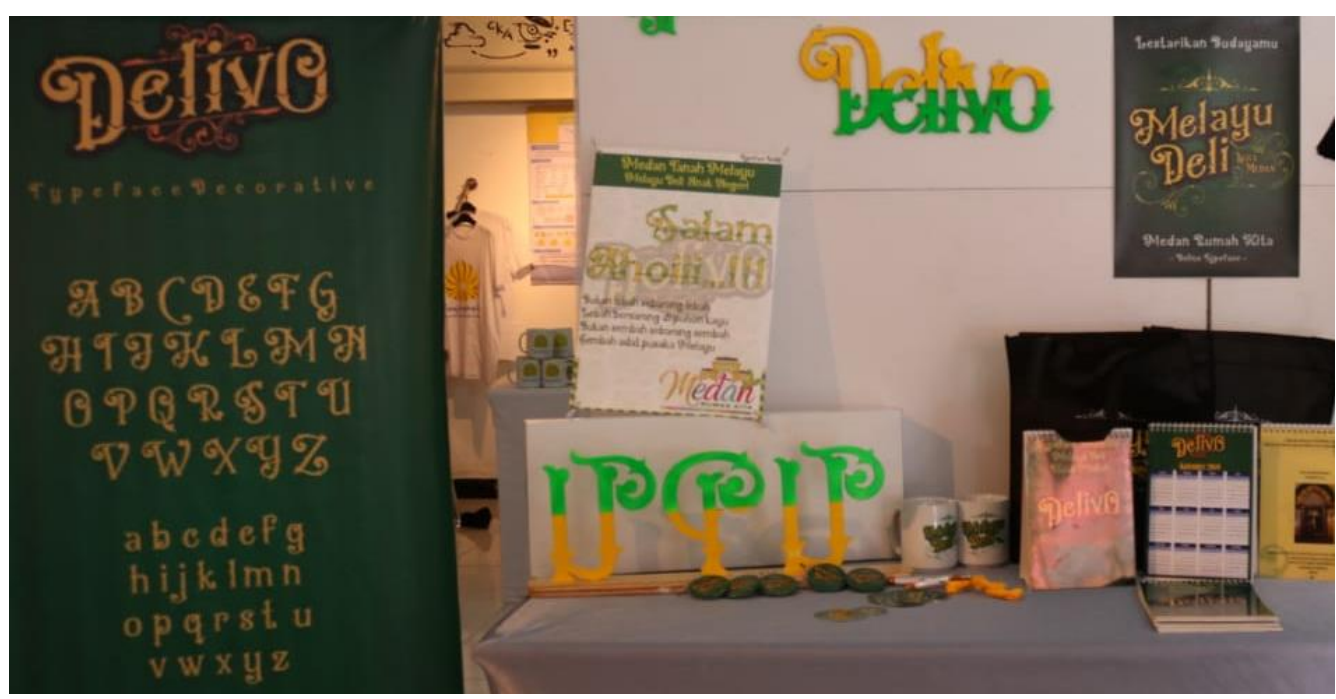

Gambar 4. Bentuk hiasan pajangan typeface delivo pada media cetak (Sumber : Ivo Ramadhani, 2018)

3. Penerapan typeface delivo pada media berbahan kayu diukir berdasarkan kata ataupun kalimat yang diinginkan menjadi hiasan pajang dinding bisa di gantung ataupun ditempelkan. 


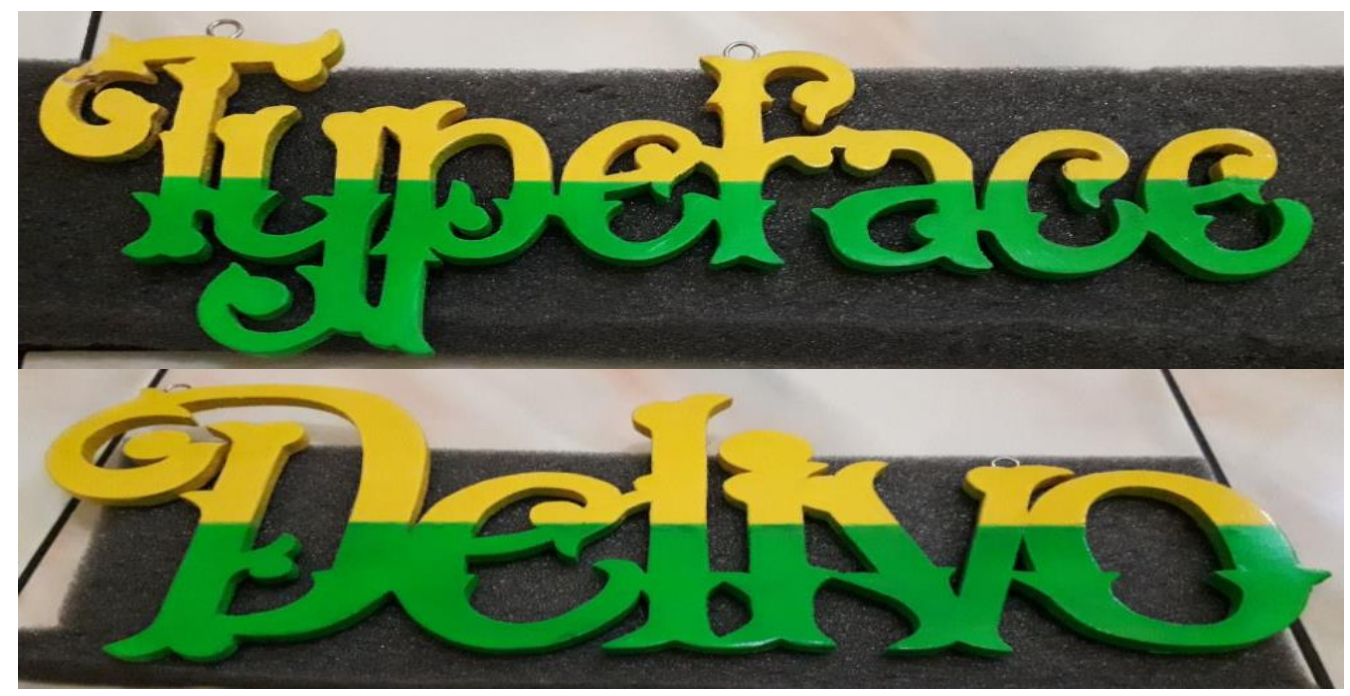

Gambar 5. Bentuk hiasan dinding typeface delivo pada media kayu tripleks (Sumber : Ivo Ramadhani, 2018)

Gambar diatas merupakan contoh bentuk penerapan typeface delivo pada media kayu dengan teknik ukir yang menyerupai karakter dari huruf typeface delivo tersebut. Penerapan huruf typeface delivo dapat diinspirasikan kebeberapa media dengan menggunakan teknik desain lainnya seperti teknik cetak maupun teknik mural pada dinding interior.

Pengolahan typeface delivo pada gambar diatas berupa kerajinan yang memiliki fungsi sebagai objek hias dekorasi interior sebagai benda pajangan yang lebih menonjolkan segi rupa daripada fungsinya. Secara garis besar fungsi typeface delivo yang berupa kerajinan dapat dikelompokkan menjadi 2 golongan yaitu :

a. Sebagai benda fungsional / terapan

b. Sebagai benda dekorasi / pajangan

Adapun fungsi pada zaman modern saat ini yaitu mengacu pada pemuasan fisik dan psikis, seperti dalam seni bangun, furniture, seni desain dan seni lainnya.

\section{KESIMPULAN}

Typeface delivo merupakan hasil rancangan jenis huruf dekoratif berdasarkan ide gagasan motif ragam hias Melayu Deli kota Medan yang dirancang kedalam bentuk soft file data font (software). Jenis huruf typeface delivo juga dapat diaplikasikan sebagai media hias dekorasi ruang interior dengan meniru huruf typeface delivo sebagai alternatif pemilihan hiasan dekorasi dinding ruang interior. Pemanfaatan typeface delivo dapat dijadikan inspirasi sebagai hiasan dekorasi berupa ukiran dengan bahan pendukung ataupun tulisan dalam bentuk media lainnya, hal ini karena typeface delivo memiliki karakter huruf yang bersifat dekoratif dan memiliki nilai estetika kebudayaan Melayu Deli.

Interior ruangan merupakan ruangan yang paling diperhatikan ketika sedang berada dalam ruangan, manusia cenderung berpersepsi. Persepsi tersebut dipengaruhi oleh indra manusia saat memasuki dan berada didalam sebuah ruang. Panca indra ini terdiri dari 
penglihatan, pendengaran, peraba, penciuman, dan perasa yang berfungsi sebagai sistem sensorik manusia. Panca indra menangkap informasi yang ada pada lingkungan sekitar dan menjadi input untuk diproses oleh otak manusia, kemudian respon dan persepsi sebagai outputnya

Penggunaan Typeface delivo memerlukan arah target penggunaan wujud dari bentuk huruf sebagai pemanfaatan hiasan ruang interior sesuai dengan gaya desain, pewarnaan dan citra interior. Target penggunaan produk Typeface delivo sebagai hiasan adalah bangun perkantoran, fasilitas umum, dan rumah hunian, yang biasanya memiliki karakteristik sebagai berikut : 1) mengutamakan produk-produk interior yang fungsional tetapi memiliki harga yang ekonomis; 2) bentuk yang disukai oleh khalayak orang yaitu seperti bentuk yang simple namun memiliki nilai estetika yang tinggi serta menonjolkan nilai kebudayaan.

\section{DAFTAR PUSTAKA}

\section{Jurnal :}

[1] Aukiyah. Afridatul, Budiono. 2017. Desain Interior "Restoran Bebek Sinjay Madura" Berkonsep Tradisional dengan Pendekatan Budaya Departemen Desain Interior, Fakultas Teknik Sipil dan Perencanaan. Surabaya: Institut Teknologi Sepuluh Nopember (ITS)

\section{Jurnal :}

[2] Pradana. Heru. 2014. Peran Mebel Sebagai Komponen Interior Program Studi Desain Interior,. Jakarta Selatan. Sekolah Tinggi Desain InterStudi

\section{Tulisan/ artikel dalam buku:}

[3] Ramadhani, Ivo. (2018). Perancangan Typeface Delivo Melalui Motif Itik Sekawan Melayu Deli. Institut Seni Indonesia Padangpanjang. Tesis

Tulisan/ artikel dalam buku:

[4] Suryajaya.Martin, 2016. Sejarah Estetika. Jakarta: Gang Kabel.

\section{Tulisan/ artikel dalam buku:}

[5] Eskak. Edi, Paramadharma. Harnandito. Pemanfaatan Center Log Kayu Sengon Untuk Pengrajin Komponen Interior.

\section{Jurnal :}

[6] Kelvianto. Nesia, Wardani.L.K 2013. Kajian Estetika Interior Restoran Sisingamangaraja Sites Semarang, Program Studi Desain Interior, Fakultas Seni dan Desain , Universitas Kristen Petra,Surakarta. 


\section{Jurnal :}

[7] Widianti,A.K, Sudianto,A.B 2017. Membaca Makna Ornamen Pepatraan Meja dan Kursi di Ruang Pengadilan Kerthagosa Klungkung Bali, Program Studi Desain Interior, Universitas Sebelas Maret ,Surabaya. 